\title{
Current situation and future prospects for global beef production: overview of special issue
}

\author{
Stephen B. Smith ${ }^{1, a, *}$, Takafumi Gotoh ${ }^{2,3, a}$, and Paul L. Greenwood ${ }^{4,5, a}$
}

* Corresponding Author: Stephen B. Smith Tel: +1-979-845-3939, Fax: +1-979-458-2702,

E-mail: sbsmith@tamu.edu

'Department of Animal Science, 2471 TAMU, Texas A\&M University, College Station, TX 77843, USA

${ }^{2}$ Department of Agricultural Sciences and Natural Resources, Faculty of Agriculture, Kagoshima

University, Kagoshima 890-0065, Japan

${ }^{3}$ Kuju Agricultural Research Center, Faculty of

Agriculture, Kyushu University, Takeda 878-0201,

Japan

${ }^{4}$ New South Wales Department of Primary Industries, Armidale Livestock Industries Centre, University of New England, Armidale NSW 2351, Australia

${ }^{5}$ CSIRO Agriculture and Food, FD McMaster Laboratory

Chiswick, Armidale NSW 2350, Australia

a These authors contributed equally to this work.

ORCID

Stephen B. Smith

https://orcid.org/0000-0002-2779-8281

Takafumi Gotoh

https://orcid.org/0000-0002-9211-9740

Paul L. Greenwood

https://orcid.org/0000-0002-7719-8233

Submitted May 29, 2018; Revised May 30, 2018; Accepted May 31, 2018

\begin{abstract}
The demand for beef as a protein source is increasing worldwide, although in most countries beef accounts for considerably less than half of total meat consumption. Beef also provides a highly desirable eating experience in developed countries and, increasingly, in developing countries. The sustainability of beef production has different meanings in the various geographical and socio-economic regions of the world. Natural resources including land mass and uses, rainfall and access to livestock feed, and the robustness of the economy are major determinants of the perception of beef sustainability. In this overview of the 2016 International Symposium on "Future Beef in Asia" and this subsequent Special Edition of the Asian-Australasian Journal of Animal Sciences on "Current Situation and Future Prospects for Global Beef Production", the contributions have been grouped into the following categories: Countries in Southeast Asia; Europe; and Countries producing highly marbled beef for export and/or domestic consumption. They also include reference to Special Topics including marbled beef production, and use of "omics" technologies to enhance beef quality assurance. Among these broad categories, notable differences exist across countries in the production and marketing of beef. These reflect differences in factors including natural resource availability and climate, population size, traditional culture and degree of economic development including industrial and technological developments. We trust that the International Symposium and this Special Edition on Current Situation and Future Prospects for Global Beef Production, the contents of which that are briefly summarized in this paper, will serve as a valuable resource for the livestock industries, researchers and students with an interest in enhancing the prospects for sustainable, efficient beef production that satisfies the growing size and complexity of consumer demands and markets for beef.
\end{abstract}

Keywords: Global Beef Production; Cattle; Production System

\section{INTRODUCTION}

This paper provides an overview of this Special Edition of the Asian-Australasian Journal of Animal Sciences on "Current Situation and Future Prospects for Global Beef Production". The Special Issue arose from the 2016 International Symposium on "Future Beef in Asia" [1] which formed part of the 17th Asian-Australasian Animal Production Animal Science Congress held from 22-25 August 2016 at Kyushu Sangyo University, Fukuoka, Japan. This symposium was organized by Dr. Takafumi Gotoh, Kyushu University \& Kagoshima University who was a member of the organizing committee of the 17th AAAP, which was also funded by the CANON Foundation and KAKENHI Grant of Japan Society for the Promotion of Science.

In Asia, more so than in many parts of the world, beef consumption dynamics are changing dramatically and rapidly due to the pace of economic development in Asian and surrounding 
countries. The growing food needs of an expanding human population, and the challenges of global climate change, have resulted in many livestock scientists in Asia focusing on the development of sustainable ruminant production systems. While the livestock industries currently provide sufficient animal-sourced foods for the global population, there is a need to improve the environmental sustainability of livestock production while increasing productivity to meet future demand. Improved productivity of beef farming systems has demonstrably reduced resource use and greenhouse gas emissions per unit of food over the past century, largely through the dilution of maintenance effect. The environmental impact of food production continues as a significant issue for all stakeholders within the supply chain, and further research is needed to ensure that comparisons among foods are based on both their environmental impact and their nutritive value to more truly assess the sustainability of ruminant and other production systems.

In several Asian countries and other emerging nations, the livestock population has increased exponentially. The recent more widespread use of concentrate feeds has improved animal growth rates and meat quality in the face of severe market competition in several industrialized nations and some developing countries. The FAO (2013) reported that the percentage of total greenhouse gasses globally produced by livestock is $14.5 \%$ [2]. There is a need to develop new feeding systems and feeds that are more effectively digested and metabolized to reduce methane emissions and increase efficiency ruminants. The question of how we should feed livestock, especially ruminants, is of great importance for the future.

Ruminants have an important ecological niche that capitalizes on the symbiotic relationship between fiber fermenting ruminal microbes and mammalian demand for digestible, usable nutrients. In other words, ruminants are valuable converters of feedstuffs not suitable for human consumption into products, particularly in the production of protein for human consumption from pasture and other forages. Future Asian beef production requires further research into ruminant feeding systems to optimize the use of pasture or other plant resources while conserving biodiversity, and into the selection and creation of supplementary protein sources, mitigation of methane emissions, food security, and the recycling of materials edible for ruminants. However, our understanding of how to do this while maintaining productivity remains limited, a problem that is addressed in this workshop. In this regard, the most important factor enabling livestock to reach their full production potential is feed conversion. New feeding regimes to enhance the sustainable, economically viable production of large quantities of quality meat by ruminants are needed.

In this Special Issue, we have grouped the contributions into the following categories: Countries in Southeast Asia [3-5]; Europe [6,7]; and Countries producing highly marbled beef for domestic [8-11] and/or export [12-14] consumption. The Special Issue also includes reference to Special Topics including marbled beef production [10], use of "omics" technologies to enhance beef quality assurance [7] and USA beef quality audits, projects and surveys [14], summaries of which have been integrated into this paper. We trust that the International Symposium and this Special Issue on Current Situation and Future Prospects for Beef Production, the contents of which that are briefly summarized below, will serve as a valuable resource for the livestock industries, researchers and students with an interest in enhancing the prospects for sustainable, efficient beef production that satisfies the growing size and complexity of consumer demands and markets for beef.

\section{DEVELOPING COUNTRIES IN SOUTHEAST ASIA}

\section{Thailand, Lao People's Democratic Republic, and Indonesia}

Increasing demand in developing countries for animal sources of food including red meat is predicted to double by 2050 . Population growth, urbanization, economic progress and changing consumer preferences are boosting the demand for livestock products in developing countries.

Thailand is a country of Native beef cattle resource farming [3]. Agricultural growth has been maintained by increasing the production of rice and cassava. Beef cattle numbers in Thailand are over 1.26 million cattle. Beef produced in Thailand has been exclusively for domestic consumption, and only a small fraction of Thailand's beef cattle are for the premium market which is based on marbling score, $40 \%$ are sold into modern markets that consider muscling of cattle, and the remainder enter traditional markets. Crossbred cattle for the premium market are raised within intensive systems, similar to Japan and Korea, where cattle are fed high-energy concentrates and roughage including rice straw. Most producers of premium beef are members of beef cooperatives, or have invested in their enterprises at high levels. Culled cows including native or crossbred cattle are mainly for small-holder farm production. Malaysia, Indonesia, and other members of the Asian Economic Community are set to become the largest beef markets in southeast Asia, which has been confirmed by 2015-2020 forecasts for consumption of beef, which must increasingly be halal. Circumstances are likely to be challenging for beef producers in Thailand to gain a share of this market.

Lao-native beef cattle are primarily Bos indicus, and most ruminant production in Laos is remains dominated by smallscale or backyard producers that use traditional practices, resulting in low productivity [4]. The cattle herd size in Laos has grown by an average of $5 \%$ per year, and the Laos cattle population now exceeds 1.88 million head, with smallholder farmers representing $98 \%$ of production. There were $170 \mathrm{com}$ - 
mercial cattle farms in 2016, with $56 \%$ in the Central region of Laos. Ruminant meat production has tended to increase, with consumption at $7.29 \mathrm{~kg} / \mathrm{capita} / \mathrm{yr}$ in 2013, but it remains insufficient to meet domestic demand. Crop residues and agroindustrial by-products used in ruminant diets include rice straw, cassava pulp and wet brewers' grains as roughage, energy and protein sources, respectively. The Belt and Road Initiative proposed by China will connect China closely with all countries in Southeast Asia. This initiative will make landlocked Laos more attractive for investors who will benefit from convenient transport at a lower cost, and hence promoting agricultural production in Laos.

Indonesia is an emerging economy, with high population growth and economic progress being the major driving forces for growing demand for animal sources of food [5]. Red meat is a traditional animal food source in Indonesia. The cattle population in Indonesia is currently about 15.4 million, of which $43 \%$ are in Java Island, $25 \%$ are in the Eastern Islands, and the remaining $32 \%$ on other islands spread around Indonesia. Average meat consumption is $2.72 \mathrm{~kg} / \mathrm{capita} / \mathrm{yr}$ and is expected to increase to $3.36 \mathrm{~kg} / \mathrm{capita} / \mathrm{yr}$ by 2020 . Java has the highest production and consumption of beef within Indonesia, with $57 \%$ of the Indonesia's population living on this island. In Indonesia, $90 \%$ of cattle production is from smallholder farming systems with about 6.5 million farmers living in rural areas, and the remaining $10 \%$ of production is from more commercial farmers that comprise $<1 \%$ of all farmers, and large beef cattle companies whose target market is concentrated in Java island. Domestic production can only satisfy about $45 \%$ of Indonesian demand for beef. To fulfil the demand for meat, the Indonesian Government has been importing meat and live feeder and slaughter cattle and some breeding stock. The high dependency on meat imports, particularly from Australia, has becomes an issue of concern for Indonesian citizens. Hence, the Indonesian government has been developing a program since 2000 for meat self-sufficiency. However, this program is not yet effective in meeting the constantly increasing demand for beef, and a more serious effort is needed to reduce the gap between local supply and demand for beef in Indonesia.

\section{EUROPE}

Despite moderate beef consumption per capita (around 16 $\mathrm{kg} / \mathrm{person} / \mathrm{yr}$ ), the European Union (EU) is the world's third largest producer of beef after the USA and Brazil, producing 7.9 million tonnes of carcasses per year [6]. Beef production contributes to the economy, rural development, social life, culture and gastronomy of European countries. The resulting diversity of breeds and animal types (cows, bulls, steers, heifers, vealers) and farming systems (intensive, extensive on permanent or temporary pastures, mixed, breeders, breeder-feeders, feeders, milk-fed, specialized or not, combined with others products) used for beef production is a strength, but also a weakness as the industry is often fragmented and poorly connected. Depending on the country, beef production is also characterized by strong societal concerns for animal welfare and the environment. Due to important regional differences in terms of climate and pasture availability, and also in terms of livestock practices and fattening farm characteristics, the productivity and incomes of beef producers vary widely across European countries and regions, being regularly among the lowest of the agricultural systems. The European beef industry is currently facing unprecedented challenges, with questions relating to animal welfare, environmental impact, origin and authenticity of beef, nutritional benefits, and consistency of eating quality. These have the potential to affect the whole industry but especially its farmers. It is therefore essential to bring the beef industry together to implement best practice, better exploit research in order to address these challenges, and to maintain and develop an economically viable and sustainable European beef industry. The challenge of meeting consumer expectations may be met by a better prediction of beef palatability using a modeling approach, such as that initially developed in Australia through the Meat Standards Australia (MSA) system. There also is a need for accurate information and its dissemination on the benefits and issues of beef for human health and also for environmental impact. A better objective description of goods and services derived from livestock farming is also required. Putting into practice "agroecology" principles and those of organic farming are other potential avenues of benefit for the future. Different scenarios for the future can be written depending on the major driving forces, notably evolution of meat consumption, climate change, environmental policies and future organization of the supply chain.

The ban on growth promotants in food producing animals in the EU is more strictly controlled than for countries outside the EU [7]. However, application regimens that are difficult to detect persist, including newly designed anabolic drugs and complex hormone cocktails. Therefore identification of molecular endogenous biomarkers which are based on the physiological response after growth promotant treatment has become a focus of detection methods. Various studies have measured gene expression changes after drug or hormone application. So-called transcriptomic biomarkers were quantified at the mRNA and/or microRNA level by RT-qPCR technology or by more modern 'omics' and high throughput technologies including RNA-sequencing. With the addition of advanced bioinformatical approaches such as hierarchical clustering analysis or dynamic principal components analysis, a valid 'biomarker signature' can be established to discriminate between treated and untreated individuals. 


\section{MAJOR COUNTRIES PRODUCING HIGHLY MARBLED BEEF}

\section{Beef production for domestic consumption}

Japan: Japan has arguably the longest tradition for producing highly marbled beef, which is known worldwide as Wagyu (literally, Japanese-style cattle) beef [8]. In Japan, Wagyu cattle include four Japanese cattle breeds: Black, Brown, Shorthorn, and Polled. Today, the renowned brand name Wagyu includes not only cattle produced in Japan, but also cattle produced in foreign countries such as Australia and the USA. In recent years, the intramuscular fat percentage in beef from Japanese Black cattle has increased beyond 30\%. The Japanese Black breed is genetically predisposed to producing carcass lipids containing higher concentrations of monounsaturated fatty acids than other breeds. Japan also has a special feeding system, using a huge amount of grain feed and controlling the level of vitamin A in the feed and blood. However, there are numerous problems concerning the management of this breed, including its high production costs, disposal of untreated excrement, the requirement for imported feed, and the food security risk resulting from numerous viral diseases introduced by imported feed. Japan experienced outbreaks of bovine spongiform encephalopathy (BSE) in September 2001 and foot and mouth disease (FMD) in 2000 and 2010. In recent years, Japan has been BSE and FMD-free. However, these earlier events caused huge economic damage and were suspected to be closely related to imported feed. In Japan, the use of animal protein has been prohibited as livestock feed since 2003 . Regarding BSE, a traceability system started in beef production of Japan in 2004, and Japan is now better managing the safety of beef production [8].

The feeding system in Japan needs to shift to one that is more efficient and provides better management for farmers, better food security for consumers, and a healthier environment for residents. Currently, metabolic programming and an ICT (IoT) management system are being developed for Wagyu beef production as future systems for beef production. If successful, we envision production of safe, high-quality Wagyu beef from domestic grass resources, including increasing areas of abandoned agricultural land and plant-based resources in Japan's mountainous areas.

Korea: Native Korean Hanwoo (pronounced Hanoo) cattle are closely, genetically related to some of the Japanese Wagyu breed types [9]. Accordingly, Hanwoo cattle share similar high marbling capacity and high monounsaturated fatty acid composition of the fat depots with Wagyu cattle, albeit not to the extremes observed in Japanese Black Wagyu cattle.

Hanwoo cattle are an important food source in Korea and their supply can have a major impact on meat availability for Korean consumers [9]. The Hanwoo cattle population was 1.8 million head in 2005 and currently exceeds 2.6 million head.
Per capita beef consumption has also increased to $11.6 \mathrm{~kg}$ per year in 2015, and is expected to continue to increase. Because intramuscular fat percentage is a critical contributor to meat quality, Hanwoo cattle are fed a high-energy corn-based diet for long fattening periods $[9,10]$. Long feeding causes significant alterations in fat percentage in the loin muscle and other areas of the carcass. However, these long feeding periods increase feeding costs and beef prices. Recently, there has been increased Korean consumer demand for lean beef, which has less fat, but is tender and priced more reasonably. These consumer demands on the Korean beef industry are driving development of differing beef production systems and also changes to the beef grading methodology. To fulfill consumer demands for beef production, the Korean government has made a significant investment to select bulls with favorable production traits using progeny testing. Progeny tested bull semen has been disseminated to all Hanwoo farmers. For a sustainable Korean beef industry, research scientists in Korea have attempted to develop precision production and marketing systems based on genetic information for Hanwoo cattle. One example of the use of the system is the beef traceability system employed for all cattle breeds in Korea since 2009. Traceability, including management information such as herd, farm, year of birth, and carcass data also help determine estimated breeding values for all Hanwoo cattle. These initiatives aim to satisfy Korean consumer demands for beef and provide more precision in beef production in Korea.

China, as a country with potential for future large-scale beef production and market demand: The beef industry is an important part of livestock and meat production in China [11]. China ranks third in the world for beef production. With the rapid development of the Chinese economy, beef consumption has grown rapidly and has been increasing with rising gross domestic production per capita. However the domestic beef industry in China has not been able to keep pace with growth in consumption, making China a net importer of beef from other countries. Moreover, the volume of production has increased little despite rising demand. The slowing of growth in beef production in recent years has led to a sharp rise in beef prices. Domestic beef production and consumption is restricted by a shortage of beef cattle inventory. The Chinese beef industry is facing many technical problems including transformation of traditional practices, feeding and management systems, and genetic improvement of cattle breeds. The longterm, sustainable development of the Chinese beef industry is an important issue for China.

\section{Beef production for export markets}

Australia: Beef production extends over almost half of Australia including agro-climatic zones varying from tropical to cool-temperate and alpine [12]. There are about 47,000 cattle producers that contribute about 20\% (\$A12.7 billion Gross 
Value of Production) of the total value of farm production in Australia. Australia is one of the world's most efficient producers of cattle and currently ranks as the world's third largest beef exporter. The Australian beef industry had 25 million head of cattle in 2016-17, with a national beef breeding herd of 11.5 million head. Australian beef production includes pasture based cow-calf systems, a backgrounding or grow-out period on pasture, and feedlot or pasture finishing.

The Australian beef export industry has been characterized by four major eras: British era prior to 1973; USA era from 1973 to 1987 which saw major expansion of Australian beef exports, primarily for manufacturing beef; the North Asian era in which beef exports increased to include higher value product to Japan and Korea from 1987 to 2009, underpinned by trade negotiations and liberalization in these countries; and the Developing Asia era since 2009, with rapid export growth to China and Indonesia in particular.

Feedlot finishing has assumed more importance in recent years to assure the eating quality of beef entering the relatively small Australian domestic market, and to enhance the supply of higher value beef for export markets. Australia has numerous temperate and tropically-adapted cattle breeds suitable for the various agro-climatic conditions and genetically selected for productivity and market related traits using the national beef genetic improvement program BREEDPLAN.

Maintenance of Australia's preferred status as a quality assured supplier of high value beef produced under environmentally sustainable systems from 'disease-free' cattle is of highest importance. Stringent livestock and meat quality regulations and quality assurance systems, and productivity growth and efficiency across the supply chain to ensure price competiveness, are crucial for continued export market growth in the face of increasing competition. At the broadest level, these issues include consumer and industry support, market growth and diversification, supply chain efficiency, productivity and profitability, environmental sustainability, and animal health and welfare.

United States of America: Beef production in the USA is principally pastoral-based, particularly for the national cowcalf herd, and spans a diverse range of climates and nutritional inputs [13]. There are 80 or so breeds of cattle in the USA, with British breeds and their crosses most prevalent. The USA had 92 million head in 2016, with 30 million beef cows, 9.3 million dairy cows, and 10.5 million cattle in feedlots at 1 January 2016. Nearly 29 million head were slaughtered in the production of 10.7 million tonnes of beef in 2015. Farm receipts total about US $\$ 88$ billion from beef production.

Unlike Australia, most U.S. beef production is for domestic consumption [13]. U.S. beef exports typically exceed 1.13 million tonnes annually, but beef imports to the USA have increased to over 1.32 million tonnes per annum. Meat consumption is the USA is high, at approximately $123 \mathrm{~kg}$ per person per year, with beef ranking second after chicken, and followed closely by pork. Domestically, there is a trend towards leaner cuts of beef. The major export markets for U.S. beef include Mexico, Japan, South Korea, Canada, Hong Kong and the Middle East with Japan, which demands more highly marbled beef, being the highest value export market for the USA.

Meat quality in the USA is a very difficult term to define because it means different things to different people [14]. When purchasing beef, consumers in the U.S. are likely to consider colour, marbling level, subcutaneous fat trim, or cut thickness when determining the quality of beef. Once consumers have consumed the product, meat quality becomes exponentially more difficult to define due to the subjective nature of this term. Traditionally, tenderness, juiciness and flavor have been considered the three most important factors that determine the palatability of beef. Therefore, American meat science beef research and industry focus has turned to measuring and quantifying these three attributes objectively and subjectively, and to determining what influences them. The U.S. beef industry and their national trade association, the National Cattlemen's Beef Association (NCBA), have conducted numerous surveys and audits to characterize the quality of the products being produced and marketed by their cattlemen and the palatability perceptions of their consumers. This has resulted in consistent measureable improvements in the eating quality of beef marketed in the USA.

Major issues for the future of the U.S. beef industry include production and marketing benefits, but also consumer concerns, about the increasing role of technologies [13]. These roles include reproduction, feeding and feed processing, animal health, animal productivity including growth promotants and genomically-enhanced genetic selection, and food safety. Water availability is also a major issue for the USA beef industry due to aquifers being depleted as a result of heavy irrigation, prompting a call to preserve this critically important resource [13]. Sustainable intensification is recognized as a priority to help meet increasing global demand for food, although it is projected that prices paid to producers of beef may decline.

\section{CONCLUSIONS}

The demand for beef as a protein source is increasing worldwide, although in most countries beef accounts for considerably less than half of total meat consumption. Beef also provides a highly desirable eating experience in developed countries and, increasingly, in developing countries. The sustainability of beef production has different meanings in the various geographical and socio-economic regions of the world. Natural resources including land mass and uses, rainfall and access to livestock feed, and the robustness of the economy are major determinants of the perception of beef sustainability. Contributions to this Special Issue include countries in Southeast 
Asia, Europe, and countries producing highly marbled beef for export and/or producing and/or importing domestic consumption. Among these broad categories, notable differences exist between countries in the production and marketing of beef. These reflect differences in factors including natural resource availability and climate, population size, traditional culture and degree of economic development including industrial and technological developments. We hope contributions to the International Symposium and Special Issue that are briefly summarized in this paper, will serve as a valuable resource for the livestock industries, researchers and students with an interest in enhancing the prospects for sustainable, efficient beef production that satisfies the growing size and complexity of consumer demands and markets for beef.

\section{CONFLICT OF INTEREST}

We certify that there is no conflict of interest with any financial organization regarding the material discussed in the manuscript.

\section{ACKNOWLEDGMENTS}

The International Symposium of "Future Beef Production in Asia" was supported by the Canon Foundation (R15-0089) and KAKENHI Grant Number 26310312 of the Japan Society for the Promotion of Science (JSPS).

\section{REFERENCES}

1. Gotoh T. International Symposium of "Future Beef Production in Asia”. 24 August 2016. 17th Asian-Australasian Animal Production Animal Science Congress. 22-25 August 2016. Kyushu Sangyo University, Fukuoka, Japan.

2. FAO. Tacking climate change through livestock: a global assessment of emissions and mitigation opportunities. Rome, Italy: FAO; 2013.

3. Bunmee T, Chaiwang N, Kaewkot C, Jaturasitha S. Current situation and future prospect of beef production in Thailand - a review. Asian-Australas J Anim Sci 2018;31:968-75.

4. Napasirth P, Napasirth V. Current situation and future prospects for beef production in Lao Peoples Democratic Republic — a review. Asian-Australas J Anim Sci 2018;31:961-7.

5. Agus A, Widi TSM. Current situation and prospect of beef cattle production in Indonesia - a review. Asian-Australas J Anim Sci 2018;31:976-83.

6. Hocquette J-F, Ellies-Oury M-P, Lherm M, et al. Current situation and future prospects for beef production in Europe - a review. Asian-Australas J Anim Sci 2018;31:1017-35.

7. Pfaffl MW, Riedmaier I. New surveillance concepts in food safety in meat producing animals: the advantage of high throughput 'omics' technologies - a review. Asian-Australas J Anim Sci 2018;31:1062-71.

8. Gotoh T, Nishimura T, Kuchida K, Mannen H. The Japanese Wagyu beef industry: current situation and future prospects - a review. Asian-Australas J Anim Sci 2018;31:933-50.

9. Chung KY, Lee SH, Lee JH. Current situation and future prospects for beef production in South Korea - a review. AsianAustralas J Anim Sci 2018;31:951-60.

10.Park SJ, Da Jung JS, Beak S-H, et al. Genetic, management, and nutritional factors affecting intramuscular fat deposition in beef cattle - a review. Asian-Australas J Anim Sci 2018;31: 1043-61.

11.Li XZ, Yan C, Zan LS. Current situation and future prospect of beef production in China - a review. Asian-Australas J Anim Sci 2018;31:984-91.

12. Greenwood PL, Gardner GE, Ferguson DM. Current situation and future prospects for the Australian beef industry - a review. Asian-Australas J Anim Sci 2018;31:992-1006.

13.Drouillard J. Current situation and future trends for beef production in the United States of America - a review. AsianAustralas J Anim Sci 2018;31:1007-16.

14. Gonzalez JM, Phelps KJ. Beef quality in the United States as chronicled by the National Beef Quality Audits, Beef Consumer Satisfaction Projects, and National Beef Tenderness Surveys - a review. Asian-Australas J Anim Sci 2018;31:1036-42. 